\title{
My Migraine Voice survey: disease impact on healthcare resource utilization, personal and working life in Finland
}

Marja-Liisa Sumelahti ${ }^{*}$, Markku Sumanen ${ }^{1}$, Merika S. Sumanen ${ }^{1}$, Samuli Tuominen ${ }^{2}$, Johanna Vikkula², Sanna M. Honkala², Stina Rosqvist ${ }^{3}$ and Minna A. Korolainen ${ }^{3,4}$

\begin{abstract}
Background: A global My Migraine Voice survey was conducted in 31 countries among 11,266 adults who suffered from $\geq 4$ monthly migraine days (MMD). The aim of this retrospective observational survey-based study was to analyse the country specific results in Finland in order to understand the impact of migraine based on disease severity.

Methods: The included participants $(3 \%, n=338 / 11,266)$ were stratified by mean MMDs into $4 \leq \mathrm{MMD}<8(n=133)$, $8 \leq \mathrm{MMD}<15(n=139)$ and $\mathrm{MMD} \geq 15(n=66)$ subgroups. Comorbidities, migraine-related emotional burden and impact on daily living and work productivity and activity impairment (WPAl) were assessed. Subgroup analysis on healthcare resource utilization ( $\mathrm{HCRU}$ ) due to migraine was assessed by visits to healthcare practitioners (HCPs) during the past 6 months and by hospitalizations and emergency room (ER) visits during the past 12 months. The group difference was tested using the one-way ANOVA and for categorical variables using the Chi-squared test. The association between HCRU and MMD and number of comorbidities was assessed using negative binomial regression analysis.
\end{abstract}

Results: Mean age was 44 years, 93\% were women and 67\% $(n=227)$ were employed. Chronic migraine (CM, MMD $\geq 15)$ was reported in $19.5 \%$ of the respondents. The negative impact on daily functioning and emotional burden increased significantly by migraine frequency. Mean number of comorbidities was 2.4, and mean number of HCP visits during the previous 6 months was 5.9. Increase in migraine frequency and comorbidities was associated with higher HCRU. Eighty-eight percent of the respondents reported negative impact on working life and 52\% experienced overall work productivity impairment. Over previous month, the mean number of missed working days for all respondents was 2.8 days of which $54 \%$ were paid sick leave days, and in CM up to 6.0 days and 30\%, respectively. Both absenteeism and presenteeism were higher in the CM group.

Conclusions: The emotional and functional burden was high, and the societal burden increased by frequency and severity of migraine, as shown by higher HCRU and reduced work productivity. There is a need to improve quality of care in migraine and improve migraine management related issues in both healthcare and society in Finland.

Keywords: Migraine, Burden, Finland, Work productivity, Quality of life, Healthcare resource utilization

\footnotetext{
* Correspondence: marja-liisa.sumelahti@tuni.fi

${ }^{1}$ Faculty of Medicine and Health Technology, Tampere University, Tampere, Finland

Full list of author information is available at the end of the article
}



(- The Author(s). 2020 Open Access This article is licensed under a Creative Commons Attribution 4.0 International License, which permits use, sharing, adaptation, distribution and reproduction in any medium or format, as long as you give appropriate credit to the original author(s) and the source, provide a link to the Creative Commons licence, and indicate if changes were made. The images or other third party material in this article are included in the article's Creative Commons licence, unless indicated otherwise in a credit line to the material. If material is not included in the article's Creative Commons licence and your intended use is not permitted by statutory regulation or exceeds the permitted use, you will need to obtain permission directly from the copyright holder. To view a copy of this licence, visit http://creativecommons.org/licenses/by/4.0/. The Creative Commons Public Domain Dedication waiver (http://creativecommons.org/publicdomain/zero/1.0/) applies to the data made available in this article, unless otherwise stated in a credit line to the data. 


\section{Background}

The estimated global prevalence of migraine is $10-15 \%$ and prevalence of chronic migraine is $1.4-2.2 \%[1,2]$. Migraine is a disabling neurological disorder that places a significant burden on the individuals but also on their family members and the whole society [3]. The impact of migraine extends beyond the physical pain of a migraine attack and it can substantially affect multiple aspects of life including day-to-day functioning, overall quality of life (QoL), emotional and social aspects such as family, work and social relationships $[3,4]$.

Migraine can be broadly classified by attack frequency into episodic migraine (EM) and chronic migraine (CM) according to the International Classification of Headache Disorders, 3rd edition (ICHD-3) [5]. EM is defined as fewer than 15 monthly migraine days (MMD), and CM as 15 or more days with headache, of which $\geq 8$ are considered migraine days. The classification has been challenged by a recent study arguing that patients suffering from high frequency migraine (MMD $\geq 8$ ) should be considered to have CM [6]. Regardless of EM or CM, the disability and burden of migraine increases along with increasing headache frequency $[7,8]$, and increasing number of migraine days equally enhances the risk for chronification of migraine [9].

Surveys across European and other countries have shown the impact of migraine on work, healthcare resource utilization (HCRU) and QoL, among other domains [10-15]. So far, My Migraine Voice survey conducted in 2017-2018 is the only survey revealing the global impact of migraine, including Finland [16]. There has been a paucity of data for the spectrum of migraine impact in the Nordic countries. Earlier studies from Finland have shown an almost 2-fold increase in healthcare visits and sick leave days when compared to age-matched counterparts [17-19]. In Sweden, a recent national patient organization survey showed a correlation between the loss in yearly quality adjusted life-years (QALYs) and increasing number of migraine days indicating that productivity loss represented a significant part of costs in migraine [20].

The aim of the present study was to focus on domains assessing the burden of migraine among Finnish $M y$ Migraine Voice survey respondents. In order to further understand the burden of migraine in a Finnish sub cohort, disease severity was assessed as MMD frequency and impact of reported comorbidities.

\section{Methods}

My Migraine Voice was a cross-sectional multi-country online survey conducted in 31 countries from September 2017 to February 2018 [16]. The Finnish participants were recruited via the Finnish Migraine Association (Patient Advocacy Group, PAG) and existing online panels from GfK Health (Growth from Knowledge, https://www.gfk.com/). Informed consent was obtained prior to the survey. Survey data were handled confidentially, and anonymity of the participants was maintained throughout the study. Ethics committee review was not required due to the research format of the study.

The Finnish cohort consisted of 345 respondents who were determined as eligible based on their responses to the screening questions. Inclusion criteria were selfreported physician diagnosed migraine based on the ICHD- 3 criteria, frequency of $\geq 4$ monthly migraine days over the previous 3 months and age $>18$ years. Respondents without migraine diagnosis $(n=7)$ were excluded from the current data-analysis.

\section{Study design}

This was a global, retrospective observational surveybased study, which consisted of closed questions. The qualitative survey was performed using online bulletin boards (OBBs) to identify the key issues relating to the professional as well as daily life experienced by individuals living with migraine. The details of the OBB survey methods has been previously published [21, 22]. The final survey comprised of 87 questions which included five country-specific questions. The questionnaire was developed by a multi-professional steering committee, consisting of migraine specialists, a specialist nurse and patient support group leaders. Detailed outcome parameters assessed in the survey including sociodemographic factors, impact on working productivity and healthcare utilization is described in detail in a report by Martelletti et al. [16]

For the purposes of this study, information was included for age, gender, family and employment status. Migraine history, frequency and severity of attacks, medication use and reported comorbidities were included. Information on healthcare resource utilization based on reported number of migraine-related visits to health care practitioners $(\mathrm{HCP})$ in the past 6 months as well as emergency room (ER) visits and inpatient days (IPD) in the past 12 months were also included. The impact of migraine on work productivity and daily activities among employed respondents was evaluated by using the Work Productivity and Activity Impairment (WPAI) questionnaire [23] and complemented with additional work-related questions. The impact of migraine on daily functioning and the migraine-related emotional burden was evaluated by responses relating to the experience of living with migraine as well as the impact on social life.

Before the analyses were carried out the participants were categorized into three groups: $4 \leq \mathrm{MMD}<8,8 \leq$ $M M D<15$ and $M M D \geq 15$, according to the reported mean monthly migraine days (MMDs) (determined by the self-reported number of migraine days in the past 3 months and divided by 3 ). 


\section{Data analysis}

For the continuous and normally distributed variables, the difference in mean between the groups was tested using the one-way ANOVA. Normality was assessed using histograms and Shapiro-Wilk test (data not shown). If the normality assumption was violated, the non-parametric Kruskall-Wallis test was utilised instead. For the categorical variables, the difference in group sizes was tested using the Chi-squared test when all the group sizes were above 5 . If at least one group size was $\leq 5$ the Fisher's exact test was utilised instead. If the number of rows in the contingence table became $\geq 7$, Monte Carlo simulation with 2000 replicates was utilised to compute the $p$-values for the Fisher's test. A significance level of 0.05 was assumed throughout the analysis.

When assessing the number of sick-leave days from work due to the migraine during the previous 1 month, the questionnaire option "I did not work at all during the previous one month" was set to equal to 23 missed workdays. When analysing questions related to the severity of pain, daily functioning and emotional burden, the questionnaire options were re-categorized into two levels instead of the original five. The options "a lot" or "often" and "always" were grouped as one level, while the rest, i.e. "no impact", "slight impact", and "moderate impact", were grouped as another level.

The work productivity and activity impairment related to a specific healthcare problem [24] (WPAI-SHP) was evaluated only for the respondents who reported current employment $(n=227)$. The WPAI outcomes are expressed as percentages of impairment, as higher WPAI percentage indicates greater impairment and lower productivity.

The relationship between healthcare resource utilization and selected predictors, i.e. age, gender, MMDs and the number of comorbidities, was assessed using regression analysis. The dependent variables, i.e. the number of $\mathrm{HCP}$ visits, ER visits and inpatient days, were over-dispersed and therefore, the negative binomial regression analysis was performed.

All analyses were conducted using $R$ (version 3.6.2) [25].

\section{Results}

\section{Patient demographics and clinical characteristics}

The total number of respondents was 345, of which 338 fulfilled the inclusion criteria. The number of respondents in subgroups according to the self-reported average number of migraine days experienced in the previous 3 months were 133 (39.3\%) for $4 \leq \mathrm{MMD}<8$ and 139 (41.4\%) for $8 \leq \mathrm{MMD}<15$ corresponding to EM, and 66 (19.5\%) for MMD $\geq 15$ corresponding to CM [5].

The demographics of the cohort and subgroups are shown in Table 1 . The majority of the respondents lived in South and West Finland (78\%). The mean age was 44 years, the majority were female (93\%), had children
(66\%) and reported a family history of migraine (86\%), with no significant difference between the subgroups. Seventy-six percent of the study participants reported migraine for 16 years or more. The respondents recruited via PAG $(n=257,76 \%)$ reported having migraine significantly longer times as compared to those recruited via GfK Health $(N=81,26 \%)$ (data shown in Additional file 1$)$.

The mean number of reported comorbidities was 2.4. Comorbidities were reported to have been diagnosed after the first migraine attack in a majority of cases (Additional file 3). The most common comorbidities were allergies (34\%), obesity (28\%), chronic gastrointestinal diseases (23\%), insomnia or sleep disorder (21\%) and chronic pain (19\%). No distribution difference between subgroups was observed.

The HCP responsible for treating migraine in the $4 \leq$ MMD $<8$ subgroup was most often a general practitioner (GP) (37\%) and in the $\mathrm{MMD} \geq 15$ a neurologist $(47 \%)$.

Reported migraine medications are shown in Table 2. Majority (94\%) reported use of acute medication, which had mainly been prescribed by their treating physician (98\%) and complemented by over-the-counter medication (OTC) (43\%). Triptans and pain relievers were most commonly used ( $81 \%$ and $80 \%$, respectively) and the use was similar in all subgroups. Thirty percent of the respondents reported using complementary non-pharmaceutical therapies.

Prophylactic treatment typically included only one medication (Additional file 4) whereas attack treatment was most often a combination of two or three medications, and use of different combinations differed significantly between MMD groups. Majority of cases (69\%) were totally or somewhat satisfied with their current acute treatment in all subgroups (Additional file 5). Minority of respondents were able to define the duration of use of their current acute medication.

Prophylactic medications used in Finland included oral medication and injectable onabotulinum toxin A (indication in $\mathrm{CM}$ ), excluding candesartan (off-label) [26]. A total of $83 \%$ reported at least one prescription for prophylactic medication during their migraine history and $77.6 \%$ of them reported one to six medication switches. The number of prophylactic medications was highest in MMD $\geq 15$ group ( $94 \%, p=0.01$ ) where up to $45 \%$ had switched the medication 6 times or more. In this cohort onabotulinum toxin A was most commonly used in $M M D \geq 15$ group and the observed use in other MMD subgroups may indicate a transformation of $\mathrm{CM}$ to EM over the treatment period.

General satisfaction to the current prophylactic medication showed different distribution in subgroups and was lowest in $M D D \geq 15$ group (Additional file 5). Sixteen questions evaluated the satisfaction for prophylactic 
Table 1 Demographics among respondents stratified by mean monthly migraine days (MMDs)

\begin{tabular}{|c|c|c|c|c|c|}
\hline & Overall & $4 \leq \mathrm{MMD}<8$ & $8 \leq \mathrm{MMD}<15$ & $\mathrm{MMD} \geq 15$ & $p$-value \\
\hline $\mathbf{N}$ & 338 & 133 & 139 & 66 & \\
\hline Age (mean (SD)) & $43.6(11.5)$ & $43.4(11.5)$ & $43.4(11.2)$ & $44.6(12.1)$ & 0.724 \\
\hline $\begin{array}{l}\text { Mean headache days incl. Migraine } \\
\text { (mean (SD)) }\end{array}$ & $12.4(6.1)$ & $8.2(4.2)$ & $12.5(4.0)$ & $20.6(4.4)$ & $<0.001$ \\
\hline \multicolumn{6}{|l|}{ Gender (\%) } \\
\hline Female & $314(92.9)$ & $123(92.5)$ & $132(95.0)$ & $59(89.4)$ & 0.339 \\
\hline Male & $24(7.1)$ & $10(7.5)$ & $7(5.0)$ & $7(10.6)$ & \\
\hline Employed & $227(67.2)$ & $92(69.2)$ & $97(69.8)$ & $38(57.6)$ & 0.180 \\
\hline \multicolumn{6}{|l|}{ Time being affected by migraine (\%) } \\
\hline $0-5$ years & $16(4.7)$ & $5(3.8)$ & $7(5.0)$ & $4(6.1)$ & 0.366 \\
\hline $6-15$ years & $73(21.6)$ & $36(27.1)$ & $26(18.7)$ & $11(16.7)$ & \\
\hline 16 or more years & $249(73.7)$ & $92(69.2)$ & $106(76.3)$ & $51(77.3)$ & \\
\hline \multicolumn{6}{|l|}{ Comorbidities } \\
\hline Chronic pain (\%) & $79(23.4)$ & $22(16.5)$ & $36(25.9)$ & $21(31.8)$ & 0.037 \\
\hline Cardiometabolic disorders (\%) & $141(41.7)$ & $62(46.6)$ & $51(36.7)$ & $28(42.4)$ & 0.250 \\
\hline Mental health-related (\%) & $118(34.9)$ & $42(31.6)$ & $49(35.3)$ & $27(40.9)$ & 0.427 \\
\hline Other (\%) & $180(53.3)$ & $68(51.1)$ & $74(53.2)$ & $38(57.6)$ & 0.692 \\
\hline \multicolumn{6}{|c|}{ Responsible HCP for treating migraine (\%) } \\
\hline General practitioner & $111(32.8)$ & $49(36.8)$ & $48(34.5)$ & $14(21.2)$ & 0.007 \\
\hline Neurologist & $111(32.8)$ & $31(23.3)$ & $49(35.3)$ & $31(47.0)$ & \\
\hline Other & $16(4.7)$ & $6(4.5)$ & $6(4.3)$ & $4(6.1)$ & \\
\hline Myself instead of any $\mathrm{HCP}$ & $77(22.8)$ & $41(30.8)$ & $26(18.7)$ & $10(15.2)$ & \\
\hline No one & $23(6.8)$ & $6(4.5)$ & $10(7.2)$ & $7(10.6)$ & \\
\hline
\end{tabular}

Age and mean headache days are presented as mean +/- SD (standard deviation) and other variables as absolute number and percentage of respondents. Grouped comorbidities are presented in more detail in the Additional file 2 $H C P$ healthcare practitioner

medication, reported in $37.0 \%$ ( $\mathrm{N} \mathrm{125/338).} \mathrm{Users} \mathrm{in} \mathrm{all}$ subgroups reported improved control over migraines in total of $39.2 \%$ and improved quality of life in $48.8 \%$.

Dissatisfaction in current prophylactic medications was evaluated in nine questions, reported in $25.9 \%(\mathrm{~N}$ $87 / 338$ ). The causes concerned mainly the lack of efficacy $(58.6 \%)$ and side-effects $(44.8 \%)$, which results were similar in all subgroups.

\section{Impact on severity of pain, daily functioning and emotional burden}

The negative impact of migraine on daily functioning and the emotional burden of migraine over the previous 1 month are described in Table 3 . In all subgroups the mean severity of pain was high, 7.5-7.8, assessed by pain severity scale from zero to 10 . Majority of cases (75\%) reported spending long periods of time in darkness or isolation.

Significant impairment was observed in quality of life domains, resulting in a negative impact of migraine on daily functioning and emotional reactions. Overall, more than $60 \%$ of the respondents reported that they had to cancel plans due to migraine and that migraine interfered with daily activities and ability to think clearly. Trouble sleeping, thoughts of hopelessness, helplessness or frustration and fear of migraine attacks were frequently reported. Both emotional reactions and problems in daily functioning showed different distribution in subgroups, difference was significant.

\section{Impact on working life}

Sixty-seven percent $(n=227)$ of the respondents were fully or part-time employed or entrepreneurs. A high proportion (90\%) reported that their current employer is aware of the migraine, whereas only $46 \%$ of the employers offered support to the migraine patients.

Eighty-eight percent of the survey participants reported that migraine had affected their overall work life (Fig. 1b). The rate differed significantly between the subgroups $(p=0.001)$. Mainly individuals in $\mathrm{MMD} \geq 15$ group reported having lost their job due to migraine $(27 \%, p<0.001)$. 
Table $\mathbf{2}$ Use of treatments among respondents overall and stratified by mean monthly migraine days (MMDs)

\begin{tabular}{|c|c|c|c|c|c|}
\hline & Overall & $4 \leq \mathrm{MMD}<8$ & $8 \leq \mathrm{MMD}<15$ & $M M D \geq 15$ & $p$-value \\
\hline $\mathbf{N}$ & 338 & 133 & 139 & 66 & \\
\hline Use of acute treatment (\%) & $319(94.4)$ & $128(96.2)$ & $129(92.8)$ & $62(93.9)$ & 0.455 \\
\hline \multicolumn{6}{|l|}{ Currently used acute medication (\%) } \\
\hline Non-opioid pain relievers & $254(80.4)$ & $101(78.9)$ & $109(85.8)$ & $44(72.1)$ & 0.074 \\
\hline Triptans & $256(81.0)$ & $98(76.6)$ & $106(83.5)$ & $52(85.2)$ & 0.240 \\
\hline Anti-emetics & $112(35.4)$ & $41(32.0)$ & $43(33.9)$ & $28(45.9)$ & 0.157 \\
\hline Any other & $70(22.2)$ & $23(18.0)$ & $25(19.7)$ & $22(36.1)$ & 0.014 \\
\hline \multicolumn{6}{|l|}{ Currently used acute treatment (\%) } \\
\hline Medicine prescribed by a doctor & $311(97.5)$ & $126(98.4)$ & $125(96.9)$ & $60(96.8)$ & 0.717 \\
\hline OTC medicine & $138(43.3)$ & $55(43.0)$ & $60(46.5)$ & $23(37.1)$ & 0.468 \\
\hline Non-medical complementary therapies* & $95(29.8)$ & $37(28.9)$ & $41(31.8)$ & $17(27.4)$ & 0.795 \\
\hline Any other & $45(14.1)$ & $15(11.7)$ & $22(17.1)$ & $8(12.9)$ & 0.449 \\
\hline Ever received prophylactic prescription (\%) & $281(83.1)$ & $103(77.4)$ & $116(83.5)$ & $62(93.9)$ & 0.010 \\
\hline \multicolumn{6}{|l|}{ Currently used prophylactic medications (\%) } \\
\hline Beta-blockers & $121(43.1)$ & 49 (47.6) & $49(42.2)$ & $23(37.1)$ & 0.409 \\
\hline Anti-epileptics & $97(34.5)$ & $29(28.2)$ & $47(40.5)$ & $21(33.9)$ & 0.157 \\
\hline Anti-depressants & $56(19.9)$ & $17(16.5)$ & $24(20.7)$ & $15(24.2)$ & 0.471 \\
\hline Onabotulinum toxin A & $43(15.3)$ & $4(3.9)$ & $17(14.7)$ & $22(35.5)$ & $<0.001$ \\
\hline Any other & $78(27.8)$ & $29(28.2)$ & $32(27.6)$ & $17(27.4)$ & 0.993 \\
\hline \multicolumn{6}{|l|}{$\begin{array}{l}\text { Number of prophylactic treatment } \\
\text { switches/failures (\%) }\end{array}$} \\
\hline Never & $63(22.4)$ & 37 (35.9) & $18(15.5)$ & $8(12.9)$ & $<0.001$ \\
\hline Once & $21(7.5)$ & $12(11.7)$ & $5(4.3)$ & $4(6.5)$ & \\
\hline Twice & $29(10.3)$ & 15 (14.6) & $10(8.6)$ & $4(6.5)$ & \\
\hline 3 times & $47(16.7)$ & $13(12.6)$ & $29(25.0)$ & $5(8.1)$ & \\
\hline 4 times & $25(8.9)$ & $8(7.8)$ & $9(7.8)$ & $8(12.9)$ & \\
\hline 5 times & $20(7.1)$ & $4(3.9)$ & $11(9.5)$ & $5(8.1)$ & \\
\hline 6 times or more & $76(27.0)$ & 14 (13.6) & $34(29.3)$ & $28(45.2)$ & \\
\hline
\end{tabular}

*Not specified

All variables are presented as absolute number and percentage of respondents OTC over-the-counter

More than one working day was missed due to migraine over the previous 1 month, the overall mean being 2.8 days, of which 1.5 (54\%) were paid sick leave days (Fig. 1c). In $M M D \geq 15$ group the average number of missed working days due to the migraine was higher, 6.0 days, and the number of paid sick leave days was only 1.8 days (31\%).

Over the past 7 days migraine caused a reduction in working time (absenteeism) in $11 \%$ and a reduction in impairment while working (presenteeism) in $48 \%$ and the corresponding rates in the $\mathrm{MMD} \geq 15$ group were $24 \%$ and $55 \%$, respectively (Fig. 1a). The overall work productivity impairment differed significantly between the subgroups being highest in the $M M D \geq 15$ group $(4 \leq \mathrm{MMD}<8: 47 \% ; 8 \leq \mathrm{MMD}<15: 53 \%$; and $\mathrm{MMD} \geq 15$ : $63 \%(p=0.01))$.
Fifty-three percent of the survey participants reported impairment in daily activities including homework, shopping and hobbies, and the outcome tended to differ between the subgroups $(p=0.06)$.

\section{Health care resource utilization}

During the previous 6 months $81 \%$ reported at least one migraine-related visit at healthcare practitioner (HCP), the mean being 5.9 visits (Fig. 2a). The number of HCP visits was higher in the MMD $\geq 15$ group compared to the $4 \leq \mathrm{MMD}<8$ group $(p=0.001)$, Fig. $2 \mathrm{a}$. The subgroups reported significantly different rates of visits at general practitioner, neurologist, and mental health professionals, including psychologist and psychiatrist $(p<0.05, p<0.001$, and $p<0.001$, respectively, Fig. $2 \mathrm{~b})$. 
Table 3 Daily functioning and emotional burden in migraine

\begin{tabular}{|c|c|c|c|c|c|}
\hline $\begin{array}{l}\text { Impact } \\
\mathrm{N}\end{array}$ & $\begin{array}{l}\text { Overall } \\
338\end{array}$ & $\begin{array}{l}4 \leq M M D<8 \\
133\end{array}$ & $\begin{array}{l}8 \leq \text { MMD }<15 \\
139\end{array}$ & $\begin{array}{l}M M D \geq 15 \\
66\end{array}$ & $p$-value \\
\hline \multicolumn{6}{|l|}{ Symptom burden } \\
\hline Severity of pain (range from 0 to 10 ; mean (SD)) & $7.6(1.5)$ & $7.5(1.5)$ & $7.6(1.5)$ & $7.8(1.3)$ & 0.570 \\
\hline Ever spent long periods in darkness or isolated (\%) & $253(74.9)$ & $94(70.7)$ & $105(75.5)$ & $54(81.8)$ & 0.227 \\
\hline $\begin{array}{l}\text { Migraine decreases the quality of life } \\
\text { ("a lot" or "significantly"; \%) }\end{array}$ & $198(58.6)$ & $52(39.1)$ & $97(69.8)$ & $49(74.2)$ & $<0.001$ \\
\hline \multicolumn{6}{|l|}{ Emotional burden } \\
\hline Often or always feeling frustrated by migraine (\%) & $200(59.2)$ & $57(42.9)$ & $99(71.2)$ & $44(66.7)$ & $<0.001$ \\
\hline Often or always feeling hopeless or helpless by migraine (\%) & $123(36.4)$ & $37(27.8)$ & $54(38.8)$ & $32(48.5)$ & 0.013 \\
\hline $\begin{array}{l}\text { Level of fear of migraine attacks } \\
\text { ("a lot" or "significantly"; \%) }\end{array}$ & $74(21.9)$ & $18(13.5)$ & $41(29.5)$ & $15(22.7)$ & 0.006 \\
\hline \multicolumn{6}{|l|}{ Daily functioning } \\
\hline Ever cancelled plans due to migraine (\%) & $317(93.8)$ & $116(87.2)$ & $136(97.8)$ & $65(98.5)$ & $<0.001$ \\
\hline $\begin{array}{l}\text { Migraine often or always interfering with ability to think clearly } \\
\text { or to focus on daily life activities and tasks (\%) }\end{array}$ & $211(62.4)$ & $59(44.4)$ & $99(71.2)$ & $53(80.3)$ & $<0.001$ \\
\hline $\begin{array}{l}\text { Level of migraine interference with daily activities } \\
\text { ("a lot" or "constantly"; \%) }\end{array}$ & $206(60.9)$ & $56(42.1)$ & $97(69.8)$ & $53(80.3)$ & $<0.001$ \\
\hline $\begin{array}{l}\text { Level of impairment in daily activity due to migraine } \\
\text { (needing to stop and rest "a lot" or "always"; \%) }\end{array}$ & $220(65.1)$ & $67(50.4)$ & $100(71.9)$ & $53(80.3)$ & $<0.001$ \\
\hline $\begin{array}{l}\text { Often or always lacking the energy to complete daily living or } \\
\text { felt fatigued (\%) }\end{array}$ & $137(40.5)$ & $38(28.6)$ & $60(43.2)$ & $39(59.1)$ & $<0.001$ \\
\hline Ever had troubles of sleeping (\%) & $250(74.0)$ & $91(68.4)$ & $102(73.4)$ & $57(86.4)$ & 0.025 \\
\hline
\end{tabular}

The impact of migraine on daily functioning and emotional reactions among respondents in subgroups by mean monthly migraine days (MMDs). Results are presented as absolute number and percentage of respondents

Overall, the survey participants visited most often a GP or a neurologist (Fig. 2b).

During the previous 12 months, 34\% reported at least one ER visit. There was a trend towards a higher number of ER visits with increasing migraine frequency (Fig. 2c). Eleven percent reported having at least one inpatient day and there was no difference between the groups (Fig. 2d).

The association of the HRCU, i.e. the number of HCP visits during the previous 6 months and the number of ER visits and inpatient days during the previous 12 months with age, gender, number of comorbidities, and MMDs, was assessed using multivariable negative binomial regression. The effect of each variable on the healthcare resource utilization was consistent throughout the HCRU types even though the impact did not reach statistical significance for all the variables (Fig. 3). A higher number of any comorbidity was associated with a higher migraine related HCRU. Also, higher number of MMDs was associated with increased HCRU with inpatient days appearing the most affected. However, the CIs are generally wider for the regression coefficients for the inpatient days as only $11 \%$ of individuals had at least one inpatient day during the previous 12 months. Note that the MMD was included as a continuous variable in the regression analysis.

\section{Discussion}

Our main results drawn from the Finnish subset of global My Migraine Voice survey data showed a tendency towards worse outcomes in a wide set of domains assessing migraine burden, consistent with increase in migraine frequency detected by MMDs. The results are consistent with observations in recently published surveys in European countries [27] and in Sweden [20]. These studies, the global My Migraine Voice survey and other observations $[13,15,28]$ indicate that individuals with episodic or chronic migraine report worse health status and negative impact on activities and working life.

The current data from Finland has not been reported previously. Majority of cases in the Finnish high frequency migraine cohort were working age and women. In the total cohort, the employment rate $(67 \%)$ corresponded to the European female employment rate in 2018 [29]. It has been estimated that a majority, $77 \%$ to $93 \%$, of all costs associated with overall migraine population are indirect and attributed to impaired or lost work productivity [20, 30, 31]. In our data, the common WPAI domains assessing indirectly the economic burden of migraine showed that over half of the respondents reported overall work impairment (absenteeism and presenteeism), and the results corroborate the reported loss in overall work productivity in other studies 


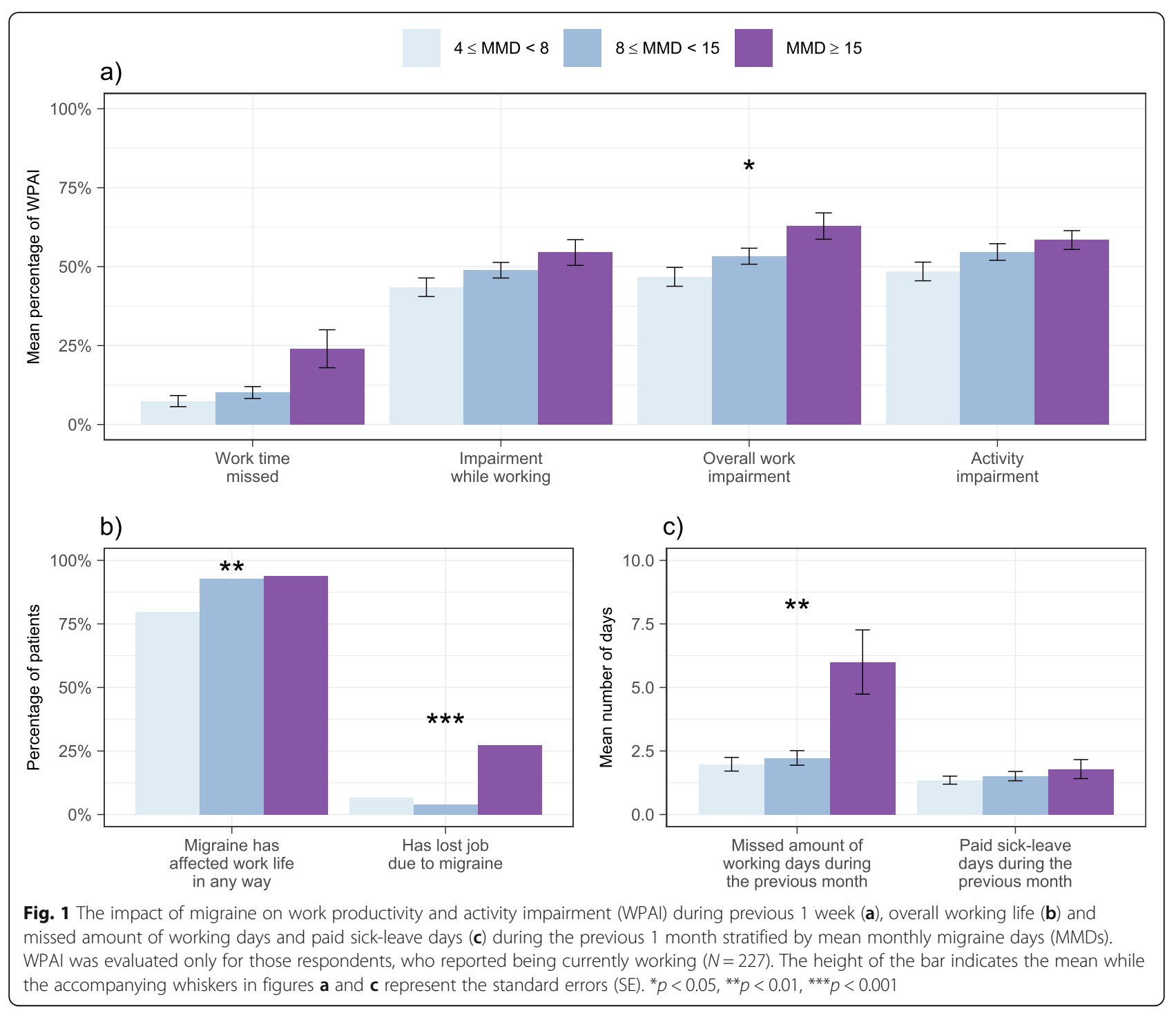

[11-13, 15]. Loss of productivity was determined by the total percentage of missed time at work, which was higher than the rate reported in the European EU5 study [27]. The increase in the mean number of missed workdays was 3-fold in CM (6 days) as compared to the other subgroups and the rates for absenteeism and presenteeism together differed between the subgroups (Fig. 1a). Furthermore, employment in CM (58\%) was lower and the rate of lost jobs (27\%) higher as compared to total in other groups.

The health care resource utilization and economic impact to the healthcare system increases along with the frequency of migraine days and the severity of migraine. Our aim was to characterize more precisely the association of migraine frequency with HCRU and facilitate the interpretation of the regression coefficients. Our results indicate that a one-day increase of monthly migraine days reflects an increase of $4 \%, 7 \%$ and $10 \%$ in HCP visits, ER visits and inpatient days, respectively. More precisely, an increase in the number of mean monthly migraine days e.g. from 5 to 20 days, equivalent to progression from the $4 \leq \mathrm{MMD}<8$ group to the $\mathrm{MMD} \geq 15$ group, indicates an increase of approximately $80 \%, 190 \%$ and $300 \%$ in HCP visits, ER visits, and inpatient days, respectively. Our results corroborate other observations and a high need of versatile HCP consultations, which increased markedly with migraine frequency. The rate of respondents reporting neurologist visits varied from $26 \%$ in $4 \leq \mathrm{MMD}<8$ up to $64 \%$ in $\mathrm{MMD} \geq 15$ group. The number of visits at GP and neurologist were frequent and the reported rates were higher than reported in European EU5 study [27] and in other European studies [32, 33]. Difference may be explained by differences in health care system and insurance practice. 


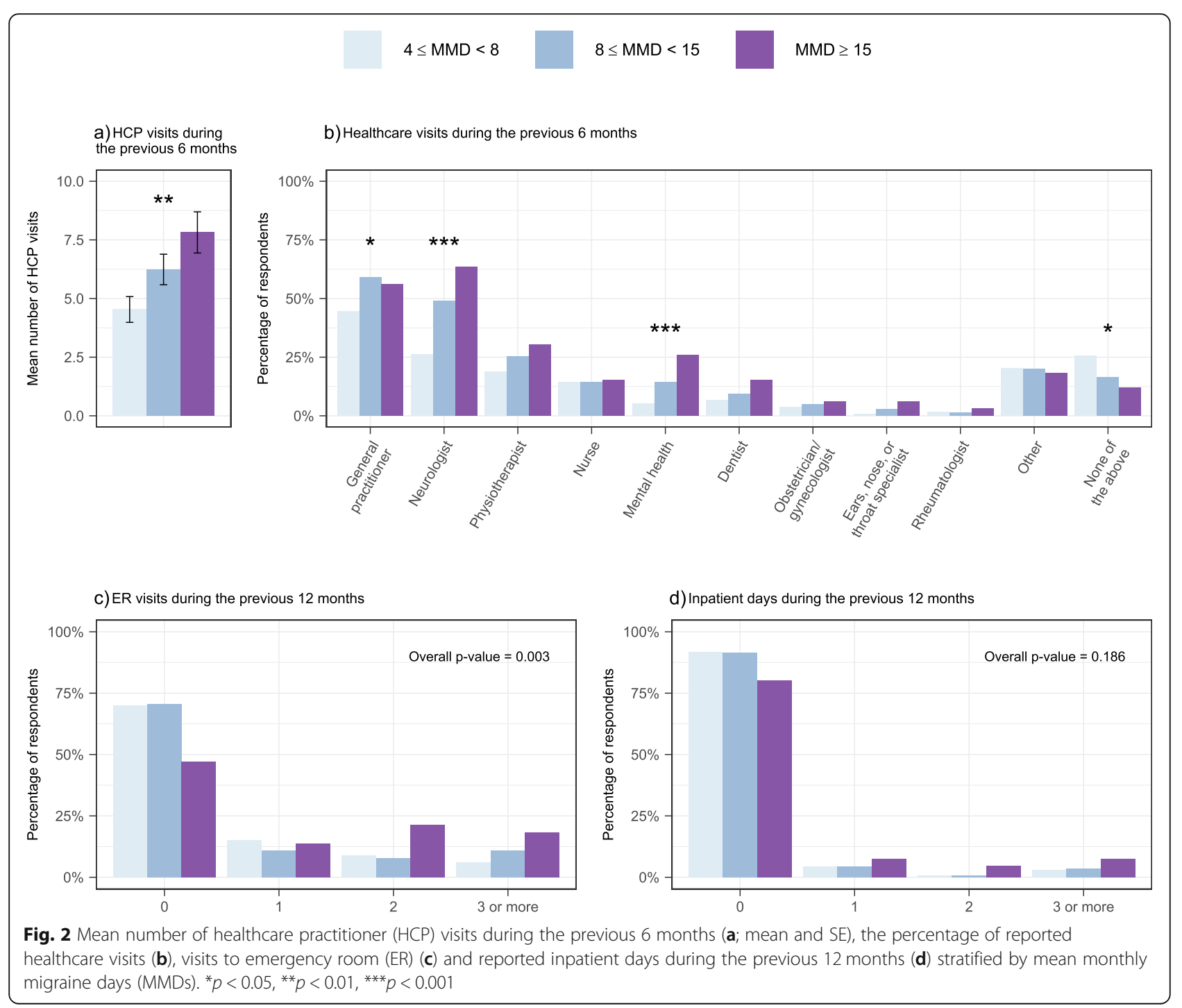

The direct costs of migraine care increase further by the presence of comorbidities [12, 34, 35]. Our results on increasing $\mathrm{HCP}$ visits, inpatient days and ER visits by both severity of migraine and comorbidities are consistent with these studies. Mental health related issues in migraine are frequent and lifetime prevalence of depression is high, reports varying from 18.8 to $42 \%$ [36-38]. The reported mental health issues in our data, most often insomnia, anxiety and depression, were reported in $35 \%$ of the total cohort and in $41 \%$ of those individuals with $\mathrm{CM}$. The rate was higher than for psychiatric diseases $(22 \%)$ in a Swedish study, however the direct comparisons between studies are hampered due to use of different inclusion of the reported diseases. A study among Finnish migraine families demonstrated that especially women were likely to have additional disorders, such as hypotension, allergies and psychiatric disorders besides their migraine [18]. Other comorbidities frequently related to migraine are painful musculoskeletal disorders reported in a Finnish study among working aged suffering from migraine [39]. Among the Finnish My Migraine Voice survey participants rheumatoid arthritis, chronic joint inflammation, fibromyalgia and chronic back pain were reported in almost one fifth $(17.8 \%)$ of all cases. This finding is in line with previous studies that have shown that migraine is highly comorbid with other chronic pain syndromes [40]. Migraine and other chronic pain syndromes have shown to enhance pain and hyperalgesia in patients with fibromyalgia [40, 41]. Cardiometabolic conditions along with several other conditions were also frequent. Increasing number of any of the reported comorbidities increased the HCP visits by $8 \%$, ER visits by $8 \%$, and inpatient days by $24 \%$. These results likely reflect the two-way 


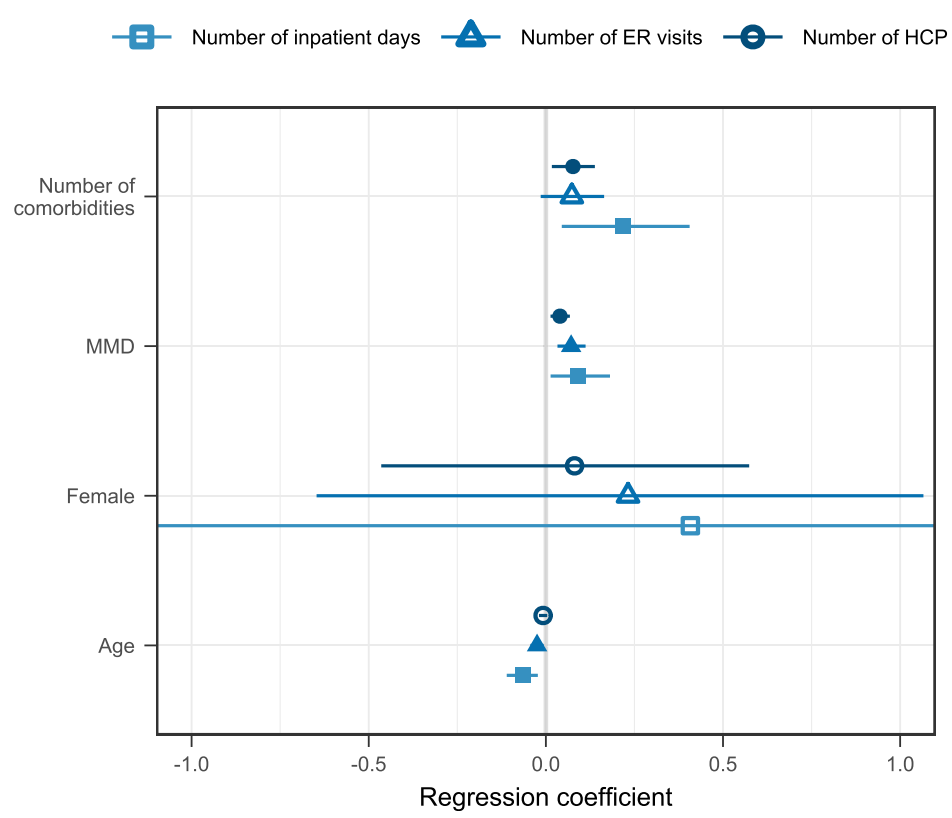

Fig. 3 Forest plot of the regression results of analysing the number of HCP visits during the previous 6 months, and the number of ER visits as well as inpatient days during the previous 12 months. The shapes indicate the regression coefficient estimate and the accompanying line indicates the $95 \% \mathrm{Cl}$. A filled shape indicates a significant association $(p<0.05)$. The $x$-axis is in the natural logarithmic scale meaning that 0.08 increase in the dependent variable (e.g. number of comorbidities for the number of HCP visits) means 1.08 actual increase, i.e. $8 \%$ increase. This increase is reflected by one unit increase in the independent variable, meaning e.g. one more comorbidity or one more monthly migraine day. Exact values of coefficients, exponentiated coefficients, Cls, and p-values are presented in Additional file 6

street of comorbidity related to frequent migraine in adult population.

The burden of migraine in My Migraine Voice survey covered several domains of the individual's personal life and emotional responses to migraine. The results point to that the majority of the respondents experience severe pain and need for isolation during attacks. Also the general negative impact on QoL increased significantly by MMD frequency. The same was true for emotional burden, including reported fear, frustration, or hopelessness. The burden of migraine is shown to relate to decreased functional ability during ictal and interictal phases [30, 31, $42,43]$ indicating that the reported emotional responses and the reported mental comorbidities are closely linked.

The majority of the individuals in this dataset were treated by a physician, which likely explains the high use of triptans in $81 \%$ and prophylactic medications in $83 \%$. These prescription patterns are considerably higher than previously reported among Finnish working-aged migraineurs [44] or in the Swedish and AMPP studies [45, 46]. Chronic migraine, failed prophylactic treatments, and several switches characterize the difficult-to-treat migraine population also in our data. Onabotulintoxin A has indication and reimbursement for CM in Finland, and the use of it was observed in all subgroups in our data, however less than that reported in a Swedish study [46]. Our results points to a transition from chronic to episodic migraine among users of onabotulinum toxin, indicated in chronic migraine. The results emphasize the need for other treatment options when traditional oral treatments fail. Today other treatments include also CGRP monoclonal antibodies [47]. The treatment escalation paradigm is supported by our observation that migraine frequency was associated with a significant change in a wide range of study parameters addressing the burden of migraine.

My Migraine Voice was not designed to be populationbased and the design was cross-sectional, and thus no follow-up data is available. Our Finnish subsample represents a small proportion of the mainly female migraine-sufferers. Also, all data in the My Migraine Voice survey was patient-reported via an online panelbased sample and there are several limitations which are inherent to these type of studies [48, 49]. Selection bias and nonresponse bias cannot be estimated in this study. Another limitation is the use of self-reported data. Selfreporting of migraine has been used in several studies and is considered reliable, supported here by a high number of respondents from PAG [50]. Also, major HCP events, like ER visits or hospitalizations, are less likely to be subjected to inaccurate recall compared to a visit to the general practitioner, however these visits or other variables of interest were not clinically confirmed. 
Certain other biases may exist; therefore, caution needs to be taken when interpreting the data. However, we assume that our findings can be generalised to most individuals having either episodic or chronic migraine.

\section{Conclusion}

We have here presented the results from the global $M y$ Migraine Voice survey in the Finnish sample and shown that the disease burden increases according to migraine severity. The cohort characterized a population where migraine exhibited the strongest effect both on working and personal life. Increase in migraine frequency was associated with greater productivity loss and use of healthcare resources as well as the effects conveyed to personal and societal level. The results point to the need to lessen this burden and to consider more active use of effective prophylactic treatments.

\section{Supplementary information}

Supplementary information accompanies this paper at https://doi.org/10. 1186/s10194-020-01185-4

Additional file 1. Prophylactic medication and time being affected by migraine stratified by recruitment path (GFK Health/ Patient Advocacy Group (PAG)). Results are presented as absolute number and percentage of respondents.

Additional file 2. Comorbidities of the study respondents overall and stratified by mean monthly migraine days (MMDs). Results are presented as absolute number and percentage of respondents.

Additional file 3. Timing of reported comorbidities in relation to the first migraine attack (before/after).

Additional file 4. Duration using each type of acute and prophylactic medication and their combinations.

Additional file 5. Satisfaction and dissatisfaction in current acute and prophylactic medication and specific causes in these groups (prophylactic medication)

Additional file 6. Results from the negative binomial regression analysis.

\section{Abbreviations}

MMD: Monthly migraine days; WPAl: Work productivity and activity impairment; HCRU: Healthcare resource utilization; HCP: Healthcare practitioner; ER: Emergency room; CM: Chronic migraine; EM: Episodic migraine; QoL: Quality of life; PAG: Patient advocacy group; OBB: Online bulletin board; IPD: Inpatient day; OTC: Over the counter

\section{Acknowledgements}

We wish to thank everyone involved in the realization of the My Migraine Voice survey, and especially the steering committee, as well as the Finnish Migraine Association and survey participants for their contribution, and Martelletti and collaborators (2018) for the study core publication.

\section{Authors' contributions}

MLS: contributed to study conception and interpretation of data, was involved in manuscript writing and revision, gave final approval for manuscript for publication, agreed to be accountable for all aspects of the work. MS: contributed to data acquisition and interpretation of data, was involved in manuscript revision, gave final approval for manuscript for publication, agreed to be accountable for all aspects of the work. MSS: contributed to data acquisition and interpretation of data, was involved in manuscript revision, gave final approval for manuscript for publication, agreed to be accountable for all aspects of the work. JV: contributed analysis and interpretation of data, was involved in manuscript writing and revision, gave final approval for manuscript for publication, agreed to be accountable for all aspects of the work. ST: contributed analysis and interpretation of data, was involved in manuscript writing and revision, gave final approval for manuscript for publication, agreed to be accountable for all aspects of the work. SMH: contributed analysis and interpretation of data, was involved in manuscript writing and revision, gave final approval for manuscript for publication, agreed to be accountable for all aspects of the work. SR: contributed to study conception and interpretation of data, was involved in manuscript writing and revision, gave final approval for manuscript for publication, agreed to be accountable for all aspects of the work. MAK: contributed to study conception and interpretation of data, was involved in manuscript writing and revision, gave final approval for manuscript for publication, agreed to be accountable for all aspects of the work.

\section{Funding}

Study was sponsored by Novartis Pharma AG and Novartis Finland. MLS, MS and MSS received no funding.

\section{Availability of data and materials}

The datasets generated and/or analyzed during the current study are not publicly available for data confidentiality reasons.

\section{Ethics approval and consent to participate}

Participants were recruited by means of existing online panels (GfK Health) and support organizations for people with migraine. Participants' consent was obtained prior to participation in the survey. Survey data were handled confidentially, and anonymity of respondents was maintained throughout the study. As such, and due to its research format, this study was exempted from ethics committee review.

\section{Consent for publication}

Not applicable.

\section{Competing interests}

SR is employed by Novartis; MK was employed by Novartis and is currently employed by Orion Coorporation; ST, JV and SMH are employed by Medaffcon. MLS, MS and MSS do not have competing interests.

\section{Author details}

${ }^{1}$ Faculty of Medicine and Health Technology, Tampere University, Tampere, Finland. ${ }^{2}$ Medaffcon Oy, Espoo, Finland. ${ }^{3}$ Novartis Finland Oy, Espoo, Finland. ${ }^{4}$ Present address: Orion Pharma, Orion Corporation, Espoo, Finland.

Received: 7 July 2020 Accepted: 17 September 2020

Published online: 29 September 2020

\section{References}

1. Stovner LJ, Nichols E, Steiner TJ, Abd-Allah F, Abdelalim A, Al-Raddadi RM et al (2018) Global, regional, and national burden of migraine and tensiontype headache, 1990-2016: a systematic analysis for the global burden of disease study 2016. Lancet Neurol 17:954-976

2. Silberstein SD, Lipton RB, Dodick DW (2014) Operational diagnostic criteria for chronic migraine: expert opinion. Headache 54:1258-1266

3. Steiner TJ, Stovner LJ, Vos T, Jensen R, Katsarava Z (2018) Migraine is first cause of disability in under 50s: will health politicians now take notice? J Headache Pain 19:17 10.1186/s10194-018-0846-2

4. Leonardi M, Raggi A (2019) A narrative review on the burden of migraine: when the burden is the impact on people's life. J Headache Pain 20:41

5. Headache Classification Committee of the International Headache Society (IHS) (2013) The International Classification of Headache Disorders, 3rd edition (beta version). Cephalalgia 33:629-808

6. Chalmer MA, Hansen TF, Lebedeva ER, Dodick DW, Lipton RB, Olesen J (2019) Proposed new diagnostic criteria for chronic migraine. Cephalalgia. 0:1-8

7. Silberstein SD, Lee L, Gandhi K, Fitzgerald T, Bell J, Cohen JM (2018) Health care resource utilization and migraine disability along the migraine continuum among patients treated for migraine: headache. Headache 58: 1579-1592

8. Katsarava Z, Buse DC, Manack AN, Lipton RB (2012) Defining the differences between episodic migraine and chronic migraine. Curr Pain Headache Rep 16:86-92 
9. Manack AN, Buse DC, Lipton RB (2011) Chronic migraine: epidemiology and disease burden. Curr Pain Headache Rep 15:70-78

10. On behalf of the Eurolight Steering Committee, Stovner LJ, Andrée C (2008) Impact of headache in Europe: a review for the Eurolight project. J Headache Pain 9:139-146

11. Stokes M, Becker WJ, Lipton RB, Sullivan SD, Wilcox TK, Wells L et al (2011) Cost of health care among patients with chronic and episodic migraine in Canada and the USA: results from the international burden of migraine study (IBMS): July/august 2011. Headache 51:1058-1077

12. Blumenfeld A, Varon S, Wilcox T, Buse D, Kawata A, Manack A et al (2011) Disability, HRQoL and resource use among chronic and episodic migraineurs: results from the international burden of migraine study (IBMS). Cephalalgia. 31:301-315

13. Buse D, Manack A, Serrano D, Reed M, Varon S, Turkel C et al (2012) Headache impact of chronic and episodic migraine: results from the American Migraine Prevalence and Prevention study. Headache 52:3-17

14. Ayzenberg I, Katsarava Z, Sborowski A, Chernysh M, Osipova V, Tabeeva G et al (2014) Headache-attributed burden and its impact on productivity and quality of life in Russia: structured healthcare for headache is urgently needed. Eur J Neurol 21:758-765

15. Adams AM, Serrano D, Buse DC, Reed ML, Marske V, Fanning KM et al (2015) The impact of chronic migraine: the chronic migraine epidemiology and outcomes (CaMEO) study methods and baseline results. Cephalalgia. 35:563-578

16. Martelletti P, Schwedt TJ, Lanteri-Minet M, Quintana R, Carboni V, Diener H$C$ et al (2018) My migraine voice survey: a global study of disease burden among individuals with migraine for whom preventive treatments have failed. J Headache Pain 19:115

17. Korolainen MA, Kurki S, Lassenius MI, Toppila I, Costa-Scharplatz M, Purmonen T et al (2019) Burden of migraine in Finland: health care resource use, sickleaves and comorbidities in occupational health care. J Headache Pain 20:13

18. Artto V, Wessman M, Nissilä M, Säkö E, Liukkonen J, Teirmaa H et al (2006) Comorbidity in Finnish migraine families. J Headache Pain 7:324-330

19. Korolainen MA, Tuominen S, Kurki S, Lassenius MI, Toppila I, Purmonen T et al (2020) Burden of migraine in Finland: multimorbidity and phenotypic disease networks in occupational healthcare. J Headache Pain 21:8

20. Hjalte F, Olofsson S, Persson U, Linde M (2019) Burden and costs of migraine in a Swedish defined patient population - a questionnaire-based study. J Headache Pain 20:65

21. Ruiz de la Torre E, Martelletti $\mathrm{P}$, Craven A. Real-world patient perspective on the burden and impact of migraine. Real-world patient perspective on the burden and impact of migraine. Vancouver September 7-10; 2017. p. Poster \#PO-02-184

22. Ruiz de la Torre E, Martelletti P, Craven A. Burden and impact of migraine: a caregiver's perspective. Burden and impact of migraine: a caregiver's perspective. Vancouver September 7-10; 2017. p. Poster \#PO-02-185

23. Reilly MC, Zbrozek AS, Dukes EM (1993) The Validity and Reproducibility of Work Productivity and Activity Impairment Instrument. Pharmacoeconomics 4:353-365

24. Reilly M. WPAI Scoring [Internet]. WPAI Scoring. Available from: http://www. reillyassociates.net/WPAl_Scoring.html. [cited 2020 Feb 26].

25. R Core Team (2017) R: A language and environment for statistical computing. R Foundation for statistical Computing, Vienna Available from: https://www.R-project.org/

26. Fimea. SPC Botox. 2019. Available from: https://spc.fimea.fi/indox/nam/html/ nam/humspc/5/10953175.pdf. [cited 2020 May 20]

27. Vo P, Fang J, Bilitou A, Laflamme AK, Gupta S (2018) Patients' perspective on the burden of migraine in Europe: a cross-sectional analysis of survey data in France, Germany, Italy, Spain, and the United Kingdom. J Headache Pain 19:82

28. Natoli J, Manack A, Dean B, Butler Q, Turkel C, Stovner L et al (2010) Global prevalence of chronic migraine: a systematic review. Cephalalgia. 30:599-609

29. Women's employment in the EU. Available from: https://ec.europa.eu/eurostat/ web/products-eurostat-news/-/EDN-20200306-1. [cited 2020 Apr 20]

30. Olesen J, Gustavsson A, Svensson M, Wittchen H-U, Jönsson B (2012) On behalf of the CDBE2010 study group, et al. the economic cost of brain disorders in Europe: economic cost of brain disorders in Europe. Eur J Neurol 19:155-162

31. Linde M, Gustavsson A, Stovner LJ, Steiner TJ, Barré J, Katsarava Z et al (2012) The cost of headache disorders in Europe: the Eurolight project: cost of headache in Europe. Eur J Neurol 19:703-711
32. Radtke A, Neuhauser H (2009) Prevalence and burden of headache and migraine in Germany. Headache 49:79-89

33. Allena M, Steiner TJ, Sances G, Carugno B, Balsamo F, Nappi G et al (2015) Impact of headache disorders in Italy and the public-health and policy implications: a population-based study within the Eurolight project. $J$ Headache Pain 16:100

34. Edmeads J, Mackell JA (2002) The economic impact of migraine: an analysis of direct and indirect costs. Headache 42:501-509

35. Bloudek LM, Stokes M, Buse DC, Wilcox TK, Lipton RB, Goadsby PJ et al (2012) Cost of healthcare for patients with migraine in five European countries: results from the international burden of migraine study (IBMS). $J$ Headache Pain 13:361-378

36. Jette N, Patten S, Williams J, Becker W, Wiebe S (2008) Comorbidity of migraine and psychiatric disorders - a National Population-Based Study. Headache 48:501-516

37. Molgat CV, Patten SB (2005) Comorbidity of major depression and migraine - a Canadian population-based study. Can J Psychiatr 50:832-837

38. Tietjen GE, Peterlin BL, Brandes JL, Hafeez F, Hutchinson S, Martin VT et al (2007) Depression and anxiety: effect on the migraine-obesity relationship. Headache 47:866-875

39. Sumelahti M-L, Mattila K, Sumanen M (2018) Painful musculosceletal disorders and depression among working aged migraineurs. Acta Neurol Scand 138:93-98

40. Affaitati G, Costantini R, Tana C, Cipollone F, Giamberardino MA (2020) Cooccurrence of pain syndromes. J Neural Transm 127:625-646

41. Giamberardino MA, Affaitati G, Martelletti P, Tana C, Negro A, Lapenna D et al (2016) Impact of migraine on fibromyalgia symptoms. J Headache Pain 17:28

42. Munakata J, Hazard E, Serrano D, Klingman D, Rupnow MFT, Tierce J et al (2009) Economic burden of transformed migraine: results from the American Migraine Prevalence and Prevention (AMPP) study. Headache 49:498-508

43. Laurell K, Artto V, Bendtsen L, Hagen K, Häggström J, Linde M et al (2016) Premonitory symptoms in migraine: a cross-sectional study in 2714 persons. Cephalalgia. 36:951-959

44. Sumelahti M-L, Mattila K, Sillanmäki L, Sumanen M (2011) Prescription patterns in preventive and abortive migraine medication. Cephalalgia. 31:1659-1663

45. Serrano D, Buse DC, Manack Adams A, Reed ML, Lipton RB (2015) Acute treatment optimization in episodic and chronic migraine: results of the American Migraine Prevalence and Prevention (AMPP) study. Headache 55:502-518

46. Frisk P, Sporrong SK, Ljunggren G, Wettermark B, von Euler M (2016) Utilisation of prescription and over-the-counter triptans: a cross-sectional study in Stockholm, Sweden. Eur J Clin Pharmacol 72:747-754

47. Tiseo C, Ornello R, Pistoia F, Sacco S (2019) How to integrate monoclonal antibodies targeting the calcitonin gene-related peptide or its receptor in daily clinical practice. J Headache Pain 20:49

48. Goren A, Liu X, Gupta S, Simon TA, Phatak H (2013) Quality of Life, Activity Impairment, and Healthcare Resource Utilization Associated with Atrial Fibrillation in the US National Health and Wellness Survey. PLoS One 8: e71264 Baradaran HR, editor

49. Kalsekar I, Wagner J-S, DiBonaventura M, Bates J, Forbes R, Hebden T (2012) Comparison of health-related quality of life among patients using atypical antipsychotics for treatment of depression: results from the National Health and wellness survey. Health Qual Life Outcomes 10:81

50. Lipton RB, Dodick D, Sadovsky R, Kolodner K, Endicott J, Hettiarachchi J et al (2003) A self-administered screener for migraine in primary care: the ID migraine $^{\mathrm{TM}}$ validation study. Neurology 61:375-382

\section{Publisher's Note}

Springer Nature remains neutral with regard to jurisdictional claims in published maps and institutional affiliations. 